\title{
How to Understand the Foundations of Empirical Belief in a Coherentist Way
}

\author{
Wolfgang Spohn \\ Fachgruppe Philosophie \\ Universität Konstanz \\ D-78434 Konstanz
}

\section{Introduction}

The discussion between foundationalism and coherentism has been around for a long time, but for about two decades it has, in a way, become more serious than before, currently forming one of the central epistemological issues. It starts from the wellknown justification trilemma which runs as follows:

Any rational subject is concerned with having rational or justified beliefs. Apparently, the only way to justify beliefs is to justify them with other beliefs which are in turn justified. This sounds obvious, but it immediately generates the trilemma: The claim that justifying beliefs have to be justified in turn triggers a regress leaving two unappealing options. Either the regress continues endlessly, in which case no one has any idea how the infinite regress could build up any justificatory force; or the regress turns back on itself, but then it seems puzzling how this circularity can avoid being vicious. Still, it is this second option coherentists venture to defend. There is a third option, namely to deny the claim generating the regress and to maintain that there are basic beliefs having justificatory force without requiring justification for themselves. This is the foundationalists' position which differentiates according to the kind of beliefs held as basic; the most usual variant is to take our perceptual or observational beliefs as basic, at least as far as our empirical beliefs are concerned.

I said that the present discussion is, in a way, more serious than before. This is so because the possibility of such basic beliefs, which many held to be obvious, has become more and more doubtful, and because coherentism has only recently found 
more precise non-metaphorical formulations which can escape the most obvious objections. In any case, I felt strongly confirmed in my coherentist prejudices by BonJour (1985) and others. ${ }^{1}$ On the other hand, it became increasingly clear that the coherentists only have a chance to convince the foundationalists if they are able to provide a compelling account of the special role of those beliefs which the foundationalists erroneously describe as basic in their special sense. I am not fully satisfied by the existing attempts to do so, and therefore I would like here to add another attempt.

This will require two preparatory explanations. The first relates to my major discontent with the whole discussion, i.e. with the fact that the relevant epistemological notions such as justification, coherence, being a reason for, etc. usually remain relatively vague. BonJour (1985) excuses himself by pointing out that the clarification of these notions is not the particular task of the coherentist. This is certainly correct. Still, the discussion would be greatly helped, I find, if it were based on precise models of our doxastic constitution which captured at least the most relevant aspects. My main motivation for this paper is that I believe myself to be in possession of such a model, though this is not the place to introduce it. Instead, as a first preliminary I will briefly sketch the epistemological outlines of this model.

The second preliminary will be concerned with how I intend to account for the epistemological role of dispositional concepts within this model. The assumption that the whole world is in principle disposed to appear to us in perception will then immediately lead to what I have to offer as a coherentist account of observation.

\section{Belief, Belief Change, Reasons, and Apriority}

Epistemology has two parts: a theory of knowledge and a theory of belief. I am concerned with the latter which is certainly more basic because doxastic notions play a crucial role in the theory of knowledge.

\footnotetext{
${ }^{1}$ Even though BonJour (forthcoming) seems to turn away from coherentism.
} 
What would a doxastic model, a theory of belief have to accomplish? Primarily, it would have to account for the statics and the dynamics of doxastic states; and it would have to do so not as a merely empirical theory, but from the perspective of a theory of rationality which leads a characteristic normative and empirical double life. The static part describes doxastic states as they rationally are at a given time; and the dynamic part describes how doxastic states rationally change over time.

Probability theory yields one very powerful model. It represents rational doxastic states as probability measures, the rational change of which is described by various rules, for instance, by the old and simple rule of conditionalization or by van Fraassen's very general reflexion principle. ${ }^{2}$ The theory of ranking functions ${ }^{3}$ which I developed fifteen years ago yields another powerful model. Ranking functions behave very much like probability measures in surprisingly many ways. They are less well suited than the latter in some important respects, but have one big and consequential advantage: They allow for a natural notion of plain belief which is difficult to capture within probability theory (as the famous lottery paradox makes clear). The notion of plain belief is also extensively dealt with in the belief systems of the AGM theory ${ }^{4}$, but I believe ranking functions exhibit a more general and satisfying dynamics than AGM belief systems.

In any case, whatever the precise theory, it seems that its dynamics cannot be stated without introducing both something like conditional doxastic states and something like degrees of belief (which need not be probabilities). This gives rise to a perfectly natural notion of reasons, i.e. of one proposition or belief content being a reason for another relative to a given doxastic state. Intuitively, what a reason would do if received is simply to strengthen the belief in for what it is a reason. In formal terms, this means that the proposition $A$ is a reason for the proposition $B$ in a given doxastic state just in case the conditional degree of belief in $B$ given $A$ is higher than that given non- $A$. In other words, the reason relation is just positive relevance.

\footnotetext{
${ }^{2}$ Cf. van Fraassen (1984) or Hild (forthcoming).

${ }^{3}$ Cf. Spohn (1988) and (1991). There I clumsily called these functions ordinal or natural conditional functions. Goldszmidt and Pearl (1992) introduced the term 'ranking functions', a terminology I like much better.

${ }^{4}$ Cf. e.g., Gärdenfors (1988) or Gärdenfors and Rott (1995).
} 
Since this notion is of central importance, one must be aware of the fact that people talk of many different justificatory relations:

There is, first and most importantly, deduction, i.e. the notion that the premises of a deductive argument are reasons for the conclusion. Positive relevance embraces this notion; a premise is positively relevant to its deductive conclusions. However, positive relevance also admits inductive, non-deductive reasoning. And fortunately so; it seems fairly clear that deductive reasoning alone is insufficient for the justification of empirical beliefs.

There is, secondly, a causal notion according to which the reasons for a belief are simply those beliefs (or possibly other items) causing its acquisition and maintenance. This diverges from positive relevance in two respects. The two notions differ in their objects. Positive relevance is a relation between belief contents ${ }^{5}$, whereas the causal notion is a relation between belief state tokens (and possibly other items, thus opening the externalist strategy of seeking justification from outside). Moreover, they refer in different ways to the dynamics of belief. As explained, positive relevance is related to the rational dynamics of belief which actualizes itself in rational subjects, whereas the causal notion refers to the actual dynamics of belief, the rationalization of which still needs to be explained. These remarks also indicate how closely related the two notions are.

Thirdly, there are computational notions of reasons formalized in various kinds of calculi. They emphasize the process character of reasoning. They may have advantages, for instance, in explaining how mathematical assertions may be justified. They fall, however, on the other side of a fundamental chasm in the theory of belief. There are semantic theories of belief which seem unable to cope with what Stalnaker (1984) calls the deduction problem, and there are computational theories of belief which are problematic in many other ways. Computational notions of reasons inherit these problems. By contrast, positive relevance, as explained, falls under the scope of semantic theories by conceiving of belief contents in a purely semantic way and not as syntactically structured. ${ }^{6}$

\footnotetext{
${ }^{5}$ Merely for stylistic variance I shall also speak of propositions or even of facts, though these terms have other uses as well.

${ }^{6}$ I have more fully discussed this chasm in Spohn (1997a). My main reason for sticking to semantic theories is that only they seem capable of capturing the normative aspect of theories of rationality.
} 
The multiplicity of concepts is certainly a main source of unclarity in epistemological discussions. The notion of coherence, or degrees of coherence, makes matters worse, insofar as its relation to the conceptions of reasons just mentioned is quite unclear in turn. The prominent notion of explanatory coherence is, however, well in line with my preference for positive relevance. If my argument in Spohn (1991) is sound, the search for explanations is tantamount to the search for positively relevant reasons in a very specific sense.

Anyway, this brief discussion indicates why I think that the notion of positive relevance which embraces deductive and inductive reasons is the most appropriate for discussing empirical belief. I shall henceforth always refer to positive relevance when talking of reasons, of support, or of justification.

This move has grave consequences which are succinctly epitomized in the following observation: According to the deductive and the causal conception the reason relation is transitive, but not symmetric; and the same holds for most computational notions (though this depends on the specific calculus). In sharp contrast to this, positive relevance is symmetric, but not transitive! This already settles the dispute, in a way, for coherentism and against foundationalism, since it immediately opts for the circular dissolution of the justification trilemma and denies basic justificatory propositions, i.e., propositions which are reasons without having reasons. ${ }^{7}$ Of course, a main task of this paper will be to make this conclusion credible.

Another central notion immediately springs from considering the dynamics of belief, the notion of apriority. It takes on two forms both of which will play an important role later:

In one sense, 'a priori' means 'unrevisable'; apriority accrues to those beliefs, or generally to those features of doxastic states, which are unrevisable and hence necessarily and always present in doxastic states. The beliefs that I exist now, or that if $p$ then $p$, are a priori in this sense. It is important to note that unrevisable beliefs like these cannot enter the reason relation. Nothing can change the status of an unrevisable belief,

\footnotetext{
${ }^{7}$ If relevance would be transitive as well as reflexive and symmetric, it would be an equivalence relation with either one equivalence class - in which case it would be absurdly universal - or several equivalence classes - in which case it would badly fail to yield coherence in any reasonable sense. So, it had better not be transitive, and it is not.
} 
hence there cannot be any reasons for or against them, and since the reason relation is symmetric, they cannot be reasons for or against other beliefs.

In another sense, 'a priori' means 'initial'. In this sense, apriority accrues to those doxastic states or parts thereof which initially obtain with respect to a given subject matter, i.e. before having any experience about it. This notion is not unproblematic, ${ }^{8}$ but not useless, either. A priori probabilities - for instance, an equal distribution over the possible results of a throw of a die - exemplify this kind of apriority; default assumptions as studied in default logic may also be taken as an example. Clearly, what is initially present need not be forever, it is revisable or defeasible. Hence, the second sense of apriority is much weaker than the first.

Both notions have a rich history, as indicated by the examples. Recent discussions have focussed on a priori justification as the key notion since it seems to provide the only route to a priori beliefs. How does this relate to my notions? On the one hand, if $a$ priori justification is to justify a priori beliefs, it can do so only in a computational sense. So, these discussions belong to another field. On the other hand, a priori justification is, in a way, easily subsumed under my notions. I have deliberately applied apriority to features of doxastic states in general. Thus, also justificatory or positive relevance relations can obtain a priori in each of the two senses; for instance, a premise is unrevisably positively relevant to its deductive consequences, and in Carnap's inductive logic certain initial positive relevancies had a central place. Indeed, such initial positive relevancies will play a crucial role in the sequel.

\section{Dispositions and Reduction Sentences}

Thus armed let me turn first to a topic prima facie unrelated: dispositions. We all know well enough what a disposition like solubility is:

\footnotetext{
${ }^{8}$ The main difficulty is this: Either, one takes 'initial' in an absolute sense in which it becomes something like 'innate'. But then it is quite obscure whether what is innate can be desribed in doxastic terms, e.g., as innate concepts. Or one relativizes 'initial' to a given subject matter (as I have implicitly done). But then one needs concepts for structuring the subject matter at hand, concepts which are to be acquired only through experience, and so the problem arises how to separate experience which is allowed to inform a (relatively) initial doxastic state from experience which turns the state into an $a$ posteriori state.
} 
(1) $\quad x$ is soluble if and only if $x$ would dissolve if it were placed in water.

Being unsure, however, of the truth conditions of subjunctives logical positivists resorted to explaining dispositions with the help of reduction sentences, i.e., sentences of the form:

(2) if $x$ is placed into water, then $x$ dissolves if and only if it is soluble.

The logical empiricists at first thought reduction sentences were analytic. But they are not, as the case of dispositions with two or more characteristic manifestations made clear; a pair of reduction sentences may have synthetic consequences. Indeed, reduction sentences are, strictly speaking, false. They hold only ceteris paribus: the presence or absence of the characteristic manifestation is not a sure sign of the presence or absence of the disposition. So, (2) should be reformulated as:

(3) if $x$ is placed in water and normal conditions obtain, then $x$ dissolves if and only if it is soluble.

Indeed, the reference to normal conditions seems ubiquitous. ${ }^{9}$ But what are they? We have to investigate, describe, and list them, but apparently they are only extensionally equivalent to such a descriptive list. Are they so defined as to make (3) true? Again no. The literal understanding is the best: The normal conditions are those conditions relevant to the case at hand which normally, or usually, obtain in our environment.

However, the real force of the reference to normal conditions emerges only when we place them into an epistemological perspective. Then it appears to be an a priori default assumption that normal conditions obtain, and the conditionals appear to express justificatory relations. In this way (3) turns into:

\footnotetext{
${ }^{9}$ Cf., e.g., Hempel (1988).
} 
(4) Given that $x$ is placed in water, the fact that $x$ is soluble is an a priori reason for assuming that $x$ dissolves (and vice versa).

Of course, the reason relation in (4) is not fixed forever. New facts can turn up in a given case on the basis of which solubility is not a reason or even a counter-reason for dissolving, and vice versa. For instance, it may turn out that the pot of water is already saturated with the stuff in question, or is exposed to unusual pressures, or is influenced by electromagnetic fields which hinder or further the dissolution. The space of further reasons, counter-reasons, and relevant conditions is to be explored only by empirical research. Still, this consideration already provides a more informative understanding of normal conditions: they are just those conditions under which the reason relation (4) continues to hold. To find out what they actually are is the task of an empirical investigation which ends with the required descriptive list, while being constrained precisely by the epistemological role of the normal conditions just given.

These observations obviously entail that the 'a priori' in (4) has to be understood in the sense of 'initially'. They also entail that the refined reduction sentence (3) is unrevisably a priori: If normal conditions are those confirming the relation between solubility and actual dissolving, any counter-reason to this relation must be an instance of non-normality; hence, (3) cannot turn out to be false. However, this is not to say that (3) is analytic. Following Kripke, I take analyticity to be a priori necessity. Thus to find out about the analyticity of (3), one would have to inquire into the metaphysical status of (3), but that would lead us astray. The unrevisability of (3), in turn, entails that the original reduction sentence (2) is a priori in the sense of being initially accepted, since we also believe prior to any investigation that normal conditions obtain. ${ }^{10}$

This analysis of solubility may suffice as an illustration of the machinery of reasons, apriority, etc. in a fairly uncontroversial case. The very same considerations, however, apply to the far more delicate case of the foundations of empirical knowledge, as I shall argue in what follows.

\footnotetext{
${ }^{10}$ All this is more fully explained in Spohn (1997b) where I also consider the metaphysical side of the matter.
} 


\section{A Thesis Concerning the Basis of Empirical Beliefs}

As an intermediate step consider briefly secondary qualities. Who would not subcribe to the following assertion?

(5) An object $x$ is red if and only if it looks red ${ }^{11}$ under normal conditions.

Nevertheless, the status of this assertion is controversial. Does it define 'red'? Is it a necessary truth? I think everything I have said about solubility applies here as well. ${ }^{12}$ The core of (5) is, again, a priori positive relevance:

(6) The fact that an object $x$ looks red is an a priori reason for assuming that $x$ is red (and vice versa).

Hence, as before, (5) is an unrevisable truth a priori, and without reference to normal conditions, it would express a defeasible belief a priori. However, (5) as it stands need not be analytic. Again this depends on the resolution of hidden ambiguities.

The next step will not be a surprise. Not only do some objects look coloured to us, the world incessantly appears to us in this and that way, at least as long as our awareness is directed outwardly. Thus we may generalize (6) to the following claim:

(7) The fact that it looks as if $p$ is an a priori reason for assuming that $p$ (and vice versa).

However, this formulation is too imprecise. Our discussion requires a more explicit version:

\footnotetext{
${ }^{11}$ Obviously it is dangerous to use the crucial phrase 'looks red' without further comment. The way I understand it here will unfold in the following sections.

${ }^{12}$ In Spohn (1997c) I more fully discuss the epistemological and metaphysical status of the various readings of (5).
} 
(8) The fact that it looks to person $x$ at time $t$ as if $p$ is an a priori reason for person $y$ to assume that $p$ (and vice versa, given that $x$ observes at $t$ the situation in which $p$ obtains $\left.{ }^{13}\right)$.

I believe that this claim is universally correct, i.e., correct in all its instantiations. The matter is extremely intricate, however, and my discussion is bound to be incomplete. Before trying to defend (8), let me briefly discuss its general significance for our epistemological concerns.

There is a characteristic indecision among foundationalists when pressed to specify the alleged basis of our empirical beliefs. They oscillate between a physicalistic and a phenomenalistic basis. A physicalistic basis contains such propositions as 'there is a computer on the table in front of me' or 'the pointer points to 2.6'. They provide a common-sense basis, in the sense that they usually need no defense. Doubts concerning basic propositions of this kind are usually not answered by argument, but by the request to look again more carefully. Still, such doubts are often legitimate; hence, this kind of basis seems to be neither really certain nor really basic. So foundationalists are driven to a phenomenalistic basis consisting of propositions about sense-data. Though sense-data belong to the more problematic species in the ontological zoo, the intended propositions can be simply expressed in common-sense terms, for example, as 'it looks to me as if there is a computer on the table in front of me' or 'the pointer seems to me to be pointing to 2.6'. This kind of basis seems both really certain and really basic. It is affected, however, by the problem how to build anything on it.

Claim (8) brings the matter into a more plausible perspective, I think. It says how the two alleged bases of the foundationalists are related. It explains why the physicalistic base is not really basic, and how something can be built upon the phenomenalistic base. Because of the symmetry of the reason relation it also does the converse and says how phenomenalistic propositions are not basic, but can have reasons, a point to which I shall have to return. Thus, (8) fits into a thoroughly coherentist picture. The reason relation claimed in (8) provides a pervasive coherentist link as a crucial building block of our

\footnotetext{
${ }^{13}$ The 'given that' clause indicates a conditional reason relation; hence it is still within the scope of this relation. The clause is not really necessary, but it guards the 'vice versa' direction from prima facie objections.
} 
empirical world view from which further coherentist links spread to other propositions about the external world more remote from observation. ${ }^{14}$ Experience may refine or even replace this building block in particular cases, but it is guaranteed to be initially present by its apriority. All of this is achieved without claiming any absolute certainties where there are none.

(8) can also be viewed as an attempt to answer skepticism, ${ }^{15}$ or a least one version of it, by showing that there is an a priori argument leading from assertions about our sense impressions to assertions about the external world. Nothing is thereby declared indubitable, and the argument is defeasible. But it is a good argument and generally applicable, and it is not prone to skeptical questions, but only to positive counter-reasons (which the skeptic refuses to provide). Obviously, however, this topic deserves much more scrutiny.

Thus, we have plenty of reasons to wish (8) to be true. Is it really true? Well, let us look at it more closely.

\section{Defending the Thesis}

Five observations concerning (8) seem to be the most relevant.

First, the domain of the propositional variable $p$ in (8) roughly consists of observation sentences such as 'there is a computer on the table in front of me' or 'the pointer points to 2.6 '. This does not mean, however, that there is a distinguished observation language ('computer' would not typically belong to it). Indeed, I do not believe in such a language. Hence, in the absence of a more precise theory about the domain of the variable $p$, we should stick to our ordinary understanding of what can be observed or perceived.

Second, it should be emphasized that assertion (8) seems perfectly reasonable when $x$ and $y$ are different persons. In one direction (8) says that we initially trust the senses of others. If they make us believe, by credible assertions or whatever, that certain things

\footnotetext{
${ }^{14}$ The metaphor of spreading is, I find, nicely explicated in the theory of Bayesian nets (cf. Pearl 1988), which works for ranking functions just as well as for probability measures.

${ }^{15}$ This kind of attempt is launched by Kutschera (1994).
} 
looked so and so to them in a particular way, we also believe that these things were that way. This conclusion can only be obviated by particular counter-reasons.

The same holds for the opposite direction. If $p$ is an observable state of affairs, as just assured, and if the person $x$ is observing the situation in which $p$ obtains, as presupposed in (8), then normally it should look to $x$ as if $p$. Again, special reasons are required for assuming otherwise. ${ }^{16}$

Third, the case where $x \neq y$ is the epistemologically less exciting one. Only the case where $x$ and $y$ are the same person is relevant to the debate between coherentists and foundationalists. To a large extent, however, this is as unproblematic as the interpersonal case. To see why, let us look more closely at the temporal relations in (8). $x$ 's observation in which certain things appear in a particular way to him takes place at a certain time $t$. However, the a priori reason relation asserted in (8) is timeless, it holds for any initial doxastic state. Still, we can apply it to a given time $t^{\prime}$, since the initial reason relation is maintained at $t^{\prime}$ if the information available to the doxastic subject up to time $t^{\prime}$ is not unfavourable.

Again there are two cases: $t$ and $t^{\prime}$ can be different times or the same time. Now it seems to me that the case where $t$ and $t^{\prime}$ are different times is like the interpersonal case. If you are reasoning now about the relation between past and future facts and the ways past and future things appear to you, you are in a similar position towards your past or future selves as you are towards other persons. I cannot see a relevant difference.

So the hard case, as to be expected, is the case where $x$ and $y$ are the same person and $t$ and $t^{\prime}$ the same time. I shall call this the reflexive case of (8). One might argue that the case cannot really occur, because as soon as we start to reason about or from how things appear to us, the appearance is already in the past, and we can reason about it only via recollection. However, this argument sounds like a lame excuse. It would be more convincing to face the problematic case, not to deny it.

Fourth, to this end we have to take a closer look at the verb 'look'. How crucially it appears in claim (8) is clear from the fact that it ultimately fixes the domain of the variable $p$. Obviously all and only such $p$ for which it makes sense to say that it looks to

\footnotetext{
${ }^{16}$ This corresponds to the negative case discussed by BonJour (1985), sect. 6.3, where the subject infers the absence of a given external state of affairs from the absence of the corresponding spontaneous belief.
} 
$x$ as if $p$ are allowed in (8). However, the treatment of this verb requires considerable delicacy, and here I cannot fully treat it. Let me make just two observations. ${ }^{17}$

On the one hand, the verb 'look' appears at least in three different constructions which are not equivalent. The fact that an object looks red to $x$, for example, is not quite the same as the fact that it looks to $x$ as if this object were red. Again, the fact that an object looks like a car to $x$ is not quite the same as the fact that it looks to $x$ as if this object were a car. Still, in the context of claim (8) these constructions seem to be exchangeable. I do not see which difference it should make to my reasoning to replace 'look as if' by 'look like' or by 'look' followed by an adjective. Hence, my remarks are intended to cover the two latter constructions as well.

On the other hand, the verb 'look' has, according to Chisholm's familiar doctrine, three different readings: the epistemic, the comparative, and the phenomenal reading. ${ }^{18} \mathrm{I}$ need not decide whether the phenomenal or the comparative reading is more adequate. The important point is that assertion (8) cannot be maintained with the epistemic reading of 'look' in the reflexive case. The reason is this: If the phrase 'looking as if $p$ ' were defined solely in doxastic terms, as it is in the epistemic reading, then (8) would claim that second-order beliefs are inductive reasons for first-order beliefs, and vice versa. This, however, contradicts the widely accepted reflexion principle of doxastic logic. This principle says that it is logically true that I believe that $p$ if and only if I believe that I believe that $p$, and thus it entails that the reason relations between second-order and firstorder beliefs are deductive and unrevisable, not defeasible, as required by (8); there is no way to drive any wedge between first-order and second-order beliefs, as it were needed for (8) to be true in the epistemic reading of 'look'. ${ }^{19}$ Hence, I have to reject the epistemic reading of 'look' as inappropriate for (8).

This conclusion may sound implausible. However, the impression of implausibility certainly derives from the fact that the verbs 'look', 'appear', and 'seem' superficially seem exchangeable, that their subtle differences, emphasized by philosophers, ${ }^{20}$ are

\footnotetext{
${ }^{17}$ I have considered the matter more thoroughly in Spohn $(1997 \mathrm{c})$.

${ }^{18}$ Cf. Chisholm (1957), ch. 4.

${ }^{19}$ I owe this point to Benkewitz (1997), sect. 5.3. The point also marks a difference to BonJour (1985), who proposes in sect. 6.3 to justify observational beliefs with reference to metabeliefs.

${ }^{20}$ Austin (1962), ch. IV. gives a paradigmatic investigation of the differences.
} 
blurred in every-day language, and that at least the verb 'seem' has a broad usage in which it expresses in the first person, or describes in the third person, nothing but a tentative or feeble belief. But 'look', ort 'sound',does have a more narrow usage according to which nothing looks any way to the blind or sounds any way to the deaf, though things may well seem to them to be red or loud or some other way. It is this narrow use, the use according to which it could not look to $x$ as if $p$ unless $x$ has a certain kind of qualia, which is intended in assertion (8).

I have argued so far that the fact that it looks to $x$ as if $p$ is a non-doxastic fact about $x$, and therefore is suited to enter $x$ 's own inductive reasoning. Yet danger threatens from another direction which is dealt with in my fifth remark.

It is often said that beliefs about introspective facts like 'this flower appears red to me' are infallible and unrevisable. This was the reason why many sought a phenomenalistic foundation of empirical knowledge. These beliefs are not a priori, of course, they do not exist all along. But once they have arisen, they seem unrevisable, at most they may be forgotten. If this were true, claim (8) taken reflexively would be in trouble again, because, as explained in section 2, unrevisable beliefs cannot enter justificatory relations. Hence, claim (8) can fully be maintained only if beliefs about such introspective facts may be mistaken and confirmed or disconfirmed by other beliefs.

Indeed, they can be mistaken for a simple, but general reason. When I come to believe that it looks to me as if $p$, I subject my sense-impressions to a certain conceptual scheme or linguistic classification, and in this I may err. Austin's well-known example of magenta is a relevant case at hand. ${ }^{21}$ But there are more far-fetched and dramatic examples to the same effect. A strong case can be built, I think, that there may be people with inverted qualia: red or reddish things look green or greenish to them, and vice versa. In fact, the hypothesis that such people actually exist has been seriously entertained on scientific grounds. ${ }^{22}$ Of course, these pseudonormal people, as they are called, do not realize this. It is very hard (and presently unfeasible) to recognize pseudonormal vision. Hence they believe that red things look red to them as to normal people, though red things actually look green to them. Nevertheless, they may find

\footnotetext{
${ }^{21}$ Cf. Austin (1962), pp. 112f.

${ }^{22}$ Nida-Rümelin (1993) and (1996) presents the hypothesis in more detail and thoroughly discusses its philosophical relevance.
} 
reason to believe in their pseudonormality. This is, after all, a scientific hypothesis confirmable in indirect and complicated ways. Thus someone may indeed learn that the ripe tomato actually looks green to him, though starting with the firm belief that it looks red.

If such examples are telling, the alleged unrevisability of the relevant introspective beliefs is cleared away - even in the seemingly hardest case of beliefs about which color things look to us. So the last obstacle to accepting (8) in the reflexive case seems to be removed, and I conclude that (8) should be endorsed in full generality. This in turn seems to license us to proceed to the favorable and exciting conclusions sketched in section 4 .

\section{The Foundationalist's Last Resort?}

Many things would still need to be said. Some remarks comparing what I have said with other theories would be in order. It would be worthwhile to extend the applications of my notion of a priori reasons, as giving it some concrete work to do was, in a way, a major point of the paper. However, the philosophically most significant continuation is perhaps the following, which I would finally at least like to indicate.

The last argument may have raised the suspicion that I have not yet done full justice to foundationalism. The argument used the fact that 'looking red', for instance, is already a linguistic concept controlled by the linguistic community. That is, when I say that something looks red to me, I am not necessarily referring to my currently experienced phenomenal quality or kind of quality. Rather, even if my utterance is taken in the phenomenal reading, I am referring to that kind of quality the experience of which most people express by that locution, and which may or may not be the one I am currently experiencing. The question which quality this is, if any, is the source of doubt, reasoning, and error just exploited by my argument. ${ }^{23}$

\footnotetext{
${ }^{23}$ The assumption that it is one and the same kind of quality which is mostly expressed by "looking red" is the presupposition characteristic of the phenomenal reading. The comparative reading does without it, and the epistemic reading even works in the case of missing qualia. Cf. Spohn (1997c).
} 
However, if this observation about the semantics of 'looking red' is correct, it follows that the state of being appeared to thus - where the 'thus' is accompanied by a sort of inner pointing - is linguistically ineffable, even if the experienced quality actually is a specific shade of red. Yet the proposition that something looks or sounds thus to me can very well be believed. There are pure concepts of phenomenal quality, even if they are ineffable ${ }^{24}$ there is undoubtedly a purely perceptual memory which is not helped by linguistic concepts, and so there are such purely phenomenal beliefs.

Hence, there seems to be a third option for basic beliefs in the foundationalist's sense. There are not only physicalistically basic propositions expressed by observation sentences $p$ or phenomenalistically basic propositions expressed by observation reports of the form 'it looks to $x$ as if $p$ ', both of which we have treated from a coherentist point of view. There are also purely phenomenal propositions. Do they save the case for foundationalism? Let us see how the picture changes when we add these purely phenomenal propositions.

First, it seems clear that propositions of the form 'it looks thus to $x$ ' are positively (or negatively) relevant to propositions of the form 'it looks to $x$ as if $p$ ', and vice versa. That something looks thus to me strongly suggests, but as we saw, does not guarantee, for instance, that it looks red to me; and that something looks red to me strongly suggests, but again does not guarantee, that it makes me experience a certain kind of quality.

Moreover, I think that this positive relevance holds a priori (if the missing qualia case is excluded). For, I can acquire, for instance, the linguistic concept 'something looks red to $x$ ' only by associating it with some purely phenomenal concept. The association may turn out to be erroneous, but I have to start with it. Hence, it is defeasibly a priori; and it obtains as long as it is not defeated.

This, finally, raises the question whether the positive relevance even holds in the problematic reflexive case. Here I feel I have no choice but to admit an exception. If I attentively look at the scene before me and it looks thus to me, I believe at the same time

\footnotetext{
${ }^{24}$ This ineffability is nothing mysterious or even impossible. One has to observe here that the concept expressed by a linguistic predicate differs in general from the property denoted by it. Thus, the claim that purely phenomenal concepts are ineffable amounts to the fact that we have no linguistic predicates for expressing these concepts. At the same time, however, these phenomenal concepts are phenomenal properties, and as such they may well be, and presumably are, denoted by linguistic predicates.
} 
that it looks thus to me, and I do not see how this belief could be supported or weakened by any reasons or counter-reasons. Has foundationalism thus got the upper hand at last? I think not, on two scores.

First, the indubitability of the belief that it currently looks thus to me is a genuine doxastic singularity. The indubitablity fades as soon as the belief turns into a recollection, and thereby it becomes accessible to doubt and reason. Hence, what I called a lame excuse above is perhaps a good excuse in this case.

Second, even if we grant the possibility of such momentarily indubitable beliefs, it would be a mistake to conclude that our empirical beliefs are ultimately based on them. Introducing the notion of direct perception, I can surely grant that the dynamics of our beliefs is basically driven by what we directly perceive. However, I take this to define what is directly perceived. It does not mean that only such purely phenomenal propositions were the objects of direct perception. On the contrary, very often we do not pay much attention to our phenomenal experience. I see, for instance, that I am standing in front of my car, I act accordingly, and I would have to reconstruct how it looked to me. Therefore, the proposition that I am standing in front of my car is what I directly perceive, it is the base or source of the belief change I thereby undergo, and at the same time it is open to reason and counter-reason.

This holds generally: The rules of rational belief change mentioned in section 2 allow us to identify the source or base of each specific change. This source, I propose, consists of the propositions directly perceived, and as my example suggests, these propositions may or may not be purely phenomenal. If this very rough sketch of direct perception can be maintained, the coherentist picture still stands.

However, I am about to open a new and large chapter in the inexhaustible book of epistemology. I should refrain.

\section{References}

Austin, John L. (1962), Sense and Sensibilia, Oxford: University Press.

Benkewitz, Wolfgang (1997), Wahrnehmen, Glauben und Gegenstände, Habilitationsschrift submitted at the University of Munich.

BonJour, Laurence (1985), The Structure of Empirical Knowledge, Cambridge, Mass.: Harvard University Press. 
BonJour, Laurence (forthcoming), 'Haack on Justification and Experience', Synthese.

Chisholm, Roderick M. (1957), Perceiving. A Philosophical Study, Ithaca: Cornell University Press.

Gärdenfors, Peter (1988), Knowledge in Flux, Cambridge, Mass.: MIT Press.

Gärdenfors, Peter, and Rott, Hans (1995), 'Belief Revision', in: D. M. Gabbay et al. (eds.), Handbook of Logic in Artificial Intelligence and Logic Programming, Vol. 4, Oxford: University Press, pp. 36-132.

Goldszmidt, Moisés, and Judea Pearl (1992), 'Default Ranking: A Practical Framework for Evidential Reasoning, Belief Revision and Update', in: Proceedings of the Third International Conference on Knowledge Representation and Reasoning, Cambridge, Mass., pp. 661-672.

Hempel, Carl G. (1988), 'Provisoes: A Problem Concerning the Inferential Function of Scientific Theories', Erkenntnis 28, 147-164.

Hild, Matthias (forthcoming), ‘The Coherence Argument Against Conditionalization', Synthese.

Kutschera, Franz (1994), 'Zwischen Skepsis und Relativismus', in: G. Meggle, U. Wessels (eds.), Analyomen 1. Perspectives in Analytical Philosophy, Berlin: de Gruyter, pp. 207-224.

Nida-Rümelin, Martine (1993), Farben und phänomenales Wissen, Wien: VWGÖ.

Nida-Rümelin, Martine (1996), 'Pseudonormal Vision: An Actual Case of Qualia Inversion?', Philosophical Studies 82, 145-157.

Pearl, Judea (1988), Probabilistic Reasoning in Intelligent Systems, San Mateo: Kaufmann.

Spohn, Wolfgang (1988), 'Ordinal Conditional Functions. A Dynamic Theory of Epistemic States', in: W.L. Harper, B. Skyrms (eds.), Causation in Decision, Belief Change, and Statistics, vol. II, Dordrecht: Kluwer, pp. 105-134.

Spohn, Wolfgang (1991), 'A Reason for Explanation: Explanations Provide Stable Reasons', in: W. Spohn, B.C. van Fraasen, B. Skyrms (eds.), Existence and Explanation. Essays Presented in Honor of Karel Lambert, Dordrecht: Kluwer, pp. 165-196.

Spohn, Wolfgang (1997a),: 'Über die Gegenstände des Glaubens', in: G. Meggle (ed.), Analyomen. Proceedings of the 2nd Conference. Vol. 1: Logic, Epistemology, and Philosophy of Science, Berlin: de Gruyter, pp. 302-333.

Spohn, Wolfgang (1997b), 'Begründungen a priori - oder: ein frischer Blick auf Dispositionsprädikate', in W. Lenzen (ed.), Das weite Spektrum der Analytischen Philosophie, Berlin: de Gruyter, pp. 323345.

Spohn, Wolfgang (1997c), 'The Character of Color Predicates: A Materialist View', in: W. Künne (ed.), Direct Reference, Indexicality and Propositional Attitudes, Stanford: CSLI Publications.

Stalnaker, Robert C. (1984), Inquiry, Cambridge, Mass.: MIT Press.

van Fraassen, Bas C. (1984), 'Belief and the Will', Journal of Philosophy 81, 235-256. 